\title{
PENGARUH PENERAPAN PENDEKATAN VARIASI TERHADAP HASIL BELAJAR TORTOR HATA SOPISIK PADA SISWA KELAS IV SD NEGERI 132403 TANJUNGBALAI
}

\author{
INDAH GUSTIANINGSIH SIREGAR \\ Prodi Pendidikan Tari
}

\begin{abstract}
This study aims to determine the effect of variations in the application of the learning outcomes approach Tortor Hata Sopisik fourth grade of SD Negeri 132403 Tanjungbalai. In this discussion the use of theories related to the topic of research is the theory of learning, learning outcomes, and approaches variation. The method used in this research is quantitative research methods. The sample in this study amounted to 34 students who are fourth grade students of SD Negeri 132403 Tanjungbalai. Instruments used in this research is to test the practice of dance. From the data acquisition is known that the learning outcomes tortor Hata Sopisik Elementary School fourth grade students 132403 Tanjungbalai before applying the variation approach into the category of less with the average value and standard deviation $=58.76=6.58$. While the study Tortor Hata Sopisik fourth grade of SD Negeri 132403 Tanjungbalai after applying a variation approach fit into both categories with the average value and standard deviation $=76.94=8.50$. Furthermore, the second data test result above the normal distribution. From the homogeneity test can be found in this sample came from a homogenous population. After tests of normality and homogeneity, obtained $t_{0}$ at 9.722 . After $t_{0}$ is known, then consulted with the table $\mathrm{t}$ the significance level of $5 \%$ with $\mathrm{df}=\mathrm{N}-1=34-1=33$ gained significance level of $5 \%=1.692$. Because $t_{0}$ obtained greater than ttable namely $9.722>1.692$, then the hypothesis is accepted. It can be concluded that there are significant variations in the application of the learning outcomes approach Tortor Hata Sopisik fourth grade of SD Negeri 132403 Tanjungbalai.
\end{abstract}

Keywords: Learning, Learning Outcomes, Approach Variation. 


\section{PENDAHULUAN}

Pendidikan di Indonesia merupakan perwujudan manusia yang bertujuan untuk mencerdaskan kehidupan bangsa berdasarkan UUD 1945. Pendidikan merupakan suatu hal yang sangat penting bagi kehidupan bangsa dan kemajuan suatu negara. Dengan adanya pendidikan bangsa Indonesia akan mengalami kemajuan dan meninggalkan suatu bentuk keterpurukan, seperti sekarang ini. Untuk itu pemerintah harus lebih berkosentrasi terhadap pendidikan di Indonesia dan juga harus membuat suatu kebijakan yang mengarahkan pada perkembangan pendidikan di Indonesia.

Pendidikan merupakan cara yang srategis untuk mencetak sumber daya manusia (SDM) yang berkualitas. Dengan kebijakan yang berkelanjutan khususnya dalam dunia pendidikan di Indonesia, bukan mustahil pendidikan di Indonesia akan menciptakan SDM yang berwawasan luas dan berkualitas. Sumber daya manusia yang berkualitas akan membawa pada kemajuan bangsa terutama dalam menjadikan masyarakat madani. Sehingga dengan adanya pendidikan yang bermutu maka semua hal yang berhubungan dengan masalah pendidikan akan cepat terselesaikan. Pendidikan yang bermutu sangat ditentukan oleh sebuah pembelajaran yang matang.

Pembelajaran dapat diartikan sebagai setiap upaya yang sistematik dan sengaja untuk menciptakan agar terjadi kegiatan interaksi edukatif antara dua pihak, yaitu antara peserta didik (warga belajar) dan pendidik (sumber belajar) yang melakukan kegiatan membelajarkan (Sudjana; 2004:28). Pembelajaran tidak hanya berlaku di dalam lingkungan sekolah saja, namun diluar lingkungan sekolah, pembelajaranpun berlaku dalam hal apapun. Dalam lingkungan sekolah, komponen utama dalam proses pembelajaran adalah guru dan siswa. Kegiatan pembelajaran merupakan proses dua arah, yaitu mengajar dan belajar. Mengajar dilakukan pihak guru sebagai pendidik, sedangkan belajar dilakukan oleh peserta didik. Kegiatan mengajar dan belajar 
tersebut terkait dengan penggunaan pendekatan dan model pembelajaran yang mengaktifkan siswa. Hubungan antara guru dengan siswa harus bersifat dinamis dan syarat makna edukasi. Untuk itu penggunaan pendekatan dan model pembelajaran harus mampu mengaktifkan siswa agar terdapat perubahan pada diri siswa dalam kegiatan belajar, untuk itu pendekatan dan model pembelajaran harus dirancang dengan baik agar kegiatan pembelajaran dapat mencapai hasil yang optimal.

Pembelajaran merupakan suatu sistem, yang terdiri dari berbagai komponen yang saling berhubungan satu dengan yang lain. Komponen tersebut meliputi: tujuan, materi, metode, dan evaluasi. Keempat komponen pembelajaran tersebut harus diperhatikan oleh guru dalam memilih dan menentukan pendekatan, dan model-model pembelajaran apa yang akan digunakan dalam kegiatan pembelajaran.

Dalam proses pembelajaran guru harus pandai menggunakan pendekatan secara arif dan bijaksana.
Pandangan guru terhadap anak didik akan menentukan sikap dan perbuatan. Setiap pendidik tidak selalu memiliki suatu pandangan yang sama dalam hal mendidik anak didik. Guru perlu menyadari dan memaklumi bahwa anak didik itu merupakan individu dengan segala perbedaannya sehingga diperlukan beberapa pendekatan.

Menurut Sanjaya (2008:127) "Pendekatan dapat diartikan sebagai titik tolak atau sudut pandang kita terhadap proses pembelajaran. Istilah pendekatan merujuk kepada pandangan tentang terjadinya suatu proses yang sifatnya masih sangat umum". Berdasarkan kajian terhadap pendapat ini, maka pendekatan merupakan langkah awal pembentukan suatu ide dalam memandang suatu masalah atau objek kajian. Pendekatan ini akan menentukan arah pelaksanaan ide tersebut untuk menggambarkan perlakuan yang diterapkan terhadap masalah atau objek kajian yang akan ditangani.

Dalam proses pembelajaran, permasalahan yang dihadapi oleh setiap anak didik biasanya bervariasi, 
maka pendekatan yang digunakan pun akan lebih tepat dengan pendekatan bervariasi pula. Pendekatan variasi adalah suatu pendekatan yang dilakukan guru untuk mengahadapi permasalahan anak didik yang bervariasi dengan menggunakan variasi teknik pemecahan masalah. Pendekatan bervariasi bertolak dari konsepsi bahwa permasalahan yang dihadapi oleh setiap anak didik dalam belajar bermacam-macam. Kasus yang biasanya muncul dalam pengajaran dengan berbagai motif, sehingga diperlukan variasi teknik pemecahan untuk setiap kasus. Maka kiranya pendekatan bervariasi ini sebagai alat yang dapat guru gunakan untuk kepentingan pengajaran.

Mata pelajaran seni budaya di

Sekolah Dasar Negeri 132403 Tanjungbalai mencakup beberapa mata pelajaran seni, yaitu seni rupa, seni musik, seni teater dan seni tari. Tujuan akhir dari pembelajaran seni budaya di sekolah adalah agar siswa mampu berkreasi, berekspresi dan berapresiasi pada seni, baik itu seni rupa, seni musik, seni teater, dan seni tari.
Menurut silabus seni budaya kelas IV Sekolah Dasar Kurikulum KTSP, salah satu materi seni tari yang akan diajarkan kepada siswa ialah memeragakan tari nusantara daerah setempat. Salah satu materi seni tari daerah setempat adalah Tortor Hata Sopisik yang berasal dari salah satu etnis yang ada di Sumatera Utara yaitu etnis Batak Toba.

Dari data awal yang diperoleh dapat diketahui bahwa jumlah nilai pre-test sebesar 1998, dengan nilai tertinggi adalah 72 dan nilai terendah adalah 48. Nilai rata-rata pre-test sebesar 58,76. Berdasarkan KKM $\geq$ 70, maka siswa yang mencapai nilai ketuntasan hanya $8,9 \%$ (3 orang), dan siswa yang belum mencapai nilai ketuntasan sebanyak $\quad 91,1 \% \quad$ (31 orang). Terdapat 3 orang siswa atau $8,9 \%$ yang termasuk dalam kategori cukup, dan 31 orang siswa atau 91,1\% yang termasuk dalam kategori kurang. Berdasarkan rata-rata sebesar 58,76 maka hasil belajar Tortor Hata Sopisik siswa kelas IV SD Negeri 132403 Tanjungbalai tergolong dalam kategori kurang. Temuan ini belum memuaskan dan perlu 
mendapatkan penerapan pendekatan variasi dalam proses pembelajaran.

Berdasarkan dari apa yang sudah dijelaskan di atas, penulis tertarik untuk meneliti bagaimana upaya untuk meningkatkan hasil belajar Tortor Hata Sopisik pada siswa kelas IV SD Negeri 132403 Tanjungbalai salah satunya dengan menerapkan pendekatan dalam proses pembelajaran yaitu pendekatan variasi. Adapun judul dalam penelitian ini adalah

"Pengaruh Penerapan Pendekatan Variasi Terhadap Hasil Belajar Tortor Hata Sopisik Pada Siswa Kelas IV SD Negeri 132403 Tanjungbalai".

\section{LANDASAN TEORI}

Untuk membahas pengaruh penerapan pendekatan variasi terhadap hasil belajar Tortor Hata Sopisik pada siswa kelas IV SD Negeri 132403 Tanjungbalai, maka penulis menggunakan teori pendekatan variasi dari Djamarah.

\section{Lokasi dan Waktu Penelitian}

Sesuai dengan judul penelitian (Pengaruh Penarapan Pendekatan Variasi Terhadap Hasil
Belajar Tortor Hata Sopisik Pada Siswa Kelas IV SD Negeri 132403 Tanjungbalai) maka penelitian dilaksanakan di SD Negeri 132403 Tanjungbalai. Waktu penelitian dilaksanakan pada tanggal 18 Juli sampai dengan 6 Agustus 2016.

\section{Populasi dan Sampel}

\section{Populasi}

Populasi dalam penelitian ini adalah siswa siswi SD Negeri 132403 Tanjungbalai.

\section{Sampel}

Sampel dalam penelitian ini adalah siswa siswi kelas IV SD Negeri 132403 Tanjungbalai yang berjumlah 34 orang.

\section{Teknik Pengumpulan Data}

Teknik pengumpulan data yang dilakukan adalah sebagai berikut:

1. Observasi

2. Dokumentasi

3. Studi Kepustakaan

4. Tes Praktik Tari

\section{Teknik Analisis Data}

Dalam penelitian ini setelah data terkumpul maka dilakuakn 
analisis adata dengan langkahlangkah sebagai berikut:

1. Menyusun data pre-test dan posttest

2. Menghitung mean hasil pre-test dan post-test (Sudijono, 2008:85):

$$
\mathrm{M}=\frac{\sum f_{x}}{N}
$$

3. Menghitung standart deviasi pretest dan post-test (Sudijono, 2008:159):

$$
S D_{X}=\sqrt{\frac{\sum f x^{2}}{N}}
$$

4. Uji Normalitas (Sudijono, 2008:283):

a. Data $\mathrm{x}_{1}, \mathrm{x}_{2}, \ldots \ldots . . \mathrm{x}_{\mathrm{n}}$, dijadikan bilangan baku $\mathrm{z}_{1}, \mathrm{z}_{2}, \ldots \ldots \ldots \mathrm{z}_{\mathrm{n}}$ dengan menggunakan rumus: $Z_{i}=\frac{x-\bar{x}}{S D_{x}} \quad\left(\bar{x}_{x} \quad\right.$ dan $\quad \mathrm{S}$ masing-masing merupakan rata-rata dan simpangan baku).

b. Menghitung peluang $\mathrm{F}(\mathrm{Zi})$ dengan menggunakan distribusi normal.

c. Selanjutnya dihitung porsi $\mathrm{z}_{1}$, $\mathrm{z}_{2}, \ldots . \mathrm{z}_{\mathrm{n}}$ yang lebih kecil atau sama dengan $\mathrm{z}_{\mathrm{i}}$.

d. Hitung selsih $\mathrm{F}(\mathrm{Zi})-\mathrm{S}(\mathrm{Zi})$, lalu tentukan harga mutlaknya.

e. Ambil harga yang paling besar di antara harga-harga mutlk selisih tersebut. Dengan harga terbesar adalah $\mathrm{L}_{0}$ dan kritis nilai L yang diambil dari daftar uji liliefors dengan taraf nyata $0,05 \quad(5 \%)$. Dengan criteria pengujian jika $\mathrm{L}_{0}<\mathrm{L}_{\text {tabel }}$ maka data berdistribusi normal dan jika $\mathrm{L}_{0}>\mathrm{L}_{\text {tabel }}$ maka data tidak berdistribusi normal.

5. Uji Homogenitas (Sudjana, 2005:249):

$$
F_{\text {hitung }}=\frac{s_{1}^{2}}{s_{2}^{2}}
$$

Pengujian homogenitas dilakukan dengan kriteria jika $\quad F_{\text {hitung }}>F_{\text {tabel }}$ menyatakan bahwa sampel berasal dari populasi yang homogen.

6. Uji Hipotesis (Sudijono, 2008:284):

$$
\mathrm{t}_{0}=\frac{M X_{2}-M X_{1}}{S E_{M X_{1}}-M X_{2}}
$$

a. Standar error mean pre-test dan post-test (Sudijono, 2008:282):

$$
S E_{M X}=\frac{S D_{X}}{\sqrt{N-1}}
$$

b. Standar error perbedaan mean pre-test dan post-test (Sudijono, 2008:283):

$$
\begin{array}{r}
S E_{M X_{1}-M X_{2}}=\sqrt{\left(S E_{M X_{1}}\right)^{2}+\left(S E_{M X_{2}}\right)^{2}} \\
\text { Dengan ketentuan jika } \mathrm{t}_{0}<\mathrm{t}_{\text {tabel }} \\
\text { pada taraf nyata } \alpha=0,05 \text { maka }
\end{array}
$$


$\mathrm{H}_{\mathrm{a}}$ ditolak, dan jika $\mathrm{t}_{0}>\mathrm{t}_{\text {tabel }}$ pada taraf nyata $\alpha=0,05$ maka $\mathrm{H}_{\mathrm{a}}$ diterima.

\section{ISI}

Hasil belajar tortor Hata Sopisik siswa kelas IV SD Negeri 132403 Tanjungbalai sebelum penerapan Pendekatan Variasi

\section{Proses Pembelajaran}

a. Guru menjelaskan materi Tortor Hata Sopisik kepada siswa

b. Guru megajarkan ragam gerak Tortor Hata Sopisik pada siswa

c. Guru membagi siswa menjadi beberapa kelompok

d. Siswa berlatih bersama kelompoknya masing-masing

e. Guru mengadakan tes hasil belajar

\section{Hasil Pembelajaran}

Dari data yang diperoleh dapat diketahui bahwa jumlah nilai pre-test sebesar 1998, dengan nilai tertinggi adalah 72 dan nilai terendah adalah 48. Nilai rata-rata pre-test sebesar 58,76. Berdasarkan KKM $\geq$ 70, maka siswa yang mencapai nilai ketuntasan hanya $8,9 \%$ (3 orang), dan siswa yang belum mencapai nilai ketuntasan sebanyak $\quad 91,1 \% \quad(31$ orang).

Terdapat 3 orang siswa atau $8,9 \%$ yang termasuk dalam kategori cukup, dan 31 orang siswa atau $91,1 \%$ yang termasuk dalam kategori kurang. Rata-rata (mean) hasil belajar Tortor Hata Sopisik sebelum menerapkan pendekatan variasi dalam proses pembelajaran yaitu:

$\mathrm{M} X_{1}=\frac{\sum f x_{1}}{N}=\frac{1998}{34}=58,76$

Berdasarkan rata-rata sebesar 58,76 maka hasil belajar Tortor Hata Sopisik siswa kelas IV SD Negeri 132403 Tanjungbalai tergolong dalam kategori kurang. Temuan ini belum memuaskan dan perlu mendapatkan penerapan pendekatan variasi dalam proses pembelajaran

Hasil belajar tortor Hata Sopisik siswa kelas IV SD Negeri 132403 Tanjungbalai sesudah diterapkan pendekatan variasi

\section{Proses Pembelajaran}

a. Guru menjelaskan materi pembelajaran Tortor Hata Sopisik

b. Sebelum mempraktikkan ragam gerak, guru 
mempertontonkan video

pembelajaran tortor Hata

Sopisik pada siswa

c. Guru mengajarkan ragam gerak tortor Hata Sopisik pada siswa

d. Guru meminta siswa untuk mempraktikkan ragam gerak Tortor Hata Sopisik

e. Guru membagi siswa menjadi 4 kelompok belajar dengan membaurkan siswa yang memiliki pintar dan kurang pintar menjadi satu kelompok pada tiap-tiap kelompok

f. Siswa mempraktikkan ragam gerak tortor Hata Sopisik perkelompok, dan guru memperbaiki teknik gerak siswa yang masih kurang baik.

g. Siswa berlatih bersama kelompoknya masing-masing, dan guru meminta siswa yang pintar untuk mengajari teman sekelompoknya yang kurang pintar (siswa yang pintar menjadi leader).

h. Dikarenakan waktu pembelajaran yang terbatas, guru mengajak siswa untuk berlatih bersama setelah pulang sekolah

i. Guru mengadakan tes hasil belajar siswa.

\section{Hasil Pembelajaran}

Dari data yang diperoleh dapat diketahui bahwa jumlah nilai post-test sebesar 2616, dengan nilai tertinggi adalah 89 dan nilai terendah adalah 60 . Nilai rata-rata post-test sebesar 76,94. Berdasarkan KKM $\geq$ 70, maka siswa yang mencapai nilai ketuntasan sebanyak $23,53 \% \quad(8$ orang), dan siswa yang belum mencapai nilai ketuntasan sebanyak $76,47 \%$ (26 orang).

Terdapat 8 orang siswa atau $23,53 \%$ yang termasuk dalam kategori kurang, 11 orang siswa atau $32,35 \%$ yang termasuk dalam kategori cukup, dan 15 orang siswa atau $44,12 \%$ yang termasuk dalam kategori baik.

Rata-rata (mean) hasil belajar tortor Hata Sopisik setelah menerapkan pendekatan variasi yaitu:

$\mathrm{M} X_{2}=\frac{\sum f x_{2}}{N}=\frac{2616}{34}=76,94$

Berdasarkan rata-rata sebesar 76,94 maka hasil belajar Tortor Hata 
Sopisik siswa kelas IV SD Negeri 132403 Tanjungbalai tergolong dalam kategori baik.

Pengaruh pendekatan variasi terhadap hasil belajar tortor Hata Sopisik siswa kelas IV SD Negeri

\section{Tanjungbalai}

\section{Uji Persyaratan Analisis}

a. Standar Deviasi Variabel $\mathrm{X}_{1}$

$S D_{X_{1}}=\sqrt{\frac{\sum f x^{2}}{N}}=\sqrt{\frac{1472,118}{34}}=\sqrt{43,297588}$ $=6,58$

b. Standar Error Variabel $\mathrm{X}_{1}$

$S E_{M X_{1}}=\frac{S D_{X_{1}}}{\sqrt{N-1}}=\frac{6,58}{\sqrt{34-1}}=\frac{6,58}{\sqrt{33}}=\frac{6,58}{5,74}$ $=1,15$

c. Standar Deviasi Variabel $\mathrm{X}_{2}$

$S D_{X_{2}}=\sqrt{\frac{\sum f x^{2}}{N}}=\sqrt{\frac{2457,882}{34}}=\sqrt{72,290647}$ $=8,50$

d. Standar Error Variabel $\mathrm{X}_{1}$

$S E_{M X_{2}}=\frac{S D_{X_{2}}}{\sqrt{N-1}}=\frac{8,50}{\sqrt{34-1}}=\frac{8,50}{\sqrt{33}}=\frac{8,50}{5,74}$ $=1,48$

\section{Uji Normalitas Data Hasil}

Belajar Sebelum Menerapkan

Pendekatan Variasi

Berdasarkan perhitungan yang telah dilakukan, harga yang paling besar di antara harga-harga mutlak selisih tersebut $\left(\mathrm{L}_{\text {hitung }}\right)=$ 0,1316. Kemudian nilai $\mathrm{L}_{\text {hitung }}$ dikonsultasikan dengan nilai kritis $\mathrm{L}$ dengan taraf nyata $\alpha 0,05$. Dimana diketahui $(\mathrm{N}=34) \quad \mathrm{L}_{\text {tabel }}=0,1519$. Dengan demikian $\quad \mathrm{L}_{\text {hitung }}<\mathrm{L}_{\text {tabel }}$ $(0,1316<0,1519)$ ini membuktikan bahwa variable $\mathrm{X}_{1}$ berdistribusi normal.

3. Uji Normalitas Data Hasil Belajar Setelah Menerapkan Pendekatan Variasi (Post-Test)

Berdasarkan perhitunagn yang telah dilakkukan, harga yang paling besar di antara harga-harga mutlak selisih tersebut ( $\left.\mathrm{L}_{\text {hitung }}\right)=$ 0,1251. Kemudian nilai $\mathrm{L}_{\text {hitung }}$ dikonsultasikan dengan nilai kritis $\mathrm{L}$ dengan taraf nyata $\alpha$ 0,05 (5\%). Dimana diketahui $(\mathrm{N}=34) \mathrm{L}_{\text {tabel }}=$ 0,1519. Dengan demikian $\mathrm{L}_{\text {hitung }}<\mathrm{L}_{\text {tabel }} \quad(0,1251<0,1519) \quad$ ini membuktikan bahwa variabl $\mathrm{X}_{2}$ berdistribusi normal.

\section{Uji Homogenitas}

Dari hasil perhitungan

diperoleh nilai dari:

Varians pada data pre-test

$\mathrm{S}_{2}{ }^{2}=43,29$

Varians pada data post-test

$\mathrm{S}_{1}^{2}=73,29$ 
Dengan diketahuinya nilainilai tersebut, maka dapat dihitung homogenitas data penelitian seperti tersaji dibawah ini:

$$
F_{\text {hitung }}=\frac{s_{1}{ }^{2}}{s_{2}{ }^{2}}=\frac{73,29}{43,29}=1,69
$$

Kriteria pengujian adalah $\mathrm{H}_{\mathrm{a}}$ diterima jika $\mathrm{F}_{\text {hitung }}<\mathrm{F}_{\text {tabel }}$ diambil $\mathrm{dk}$ pembilang adalah $\mathrm{dk}$ varians terbesar dan $\mathrm{dk}$ penyebut adalah $\mathrm{dk}$ varians terkecil. Maka diperoleh $\mathrm{F}_{\text {hitung }}=$ 1,69. Dari tabel distribusi F dengan $\alpha$ $=0,05$ diperoleh $\mathrm{F}_{\text {tabel }}=2,39$. Jadi $\mathrm{F}_{\text {hitung }}<\mathrm{F}_{\text {tabel }}$ yakni $1,69<2,39$. Hal ini membuktikan bahwa sampel $H_{a}$ yang menyatakan bahwa varians kedua variabel tersebut homogen.

\section{Pengujian Hipotesis}

\section{Berdasarkan} pengujian normalitas dan homogenitas data di atas, maka hasilnya menunjukkan bahwa persyaratan analisis dalam penelitian ini berdistribusi normal dan bervariansi populasi homogen. Hal ini menunjukkan bahwa persyaratan analisis dalam penelitian ini terpenuhi, sehingga dapat dilanjutkan pada pengujian hipotesis. Adapaun hipotesis awal dalam penelitian ini adalah terdapat pengaruh penerapan pendekatan variasi terhadap hasil belajar tortor Hata Sopisik siswa kelas IV SD Negeri 132403 Tanjungbalai. Pengujian hipotesis ini menggunakan uji " $t$ " dengan perhitungan sebagai berikut:

1. Analisis Data Pre-test

$$
\begin{aligned}
& \mathrm{M} X_{1}=58,76 \\
& S D_{X_{1}}=6,58 \\
& S E_{M X_{1}}=1,15
\end{aligned}
$$

2. Analisis Data Post-test

$$
\begin{aligned}
& \mathrm{M} X_{2}=76,94 \\
& S D_{X_{2}}=8,50 \\
& S E_{M X_{2}}=1,48
\end{aligned}
$$

Dari data-data di atas, maka diperoleh standar error perbedaan kedua hasil pre-test dan post-test yaitu:

$$
\begin{aligned}
& S E_{M X_{1}-M X_{2}}=\sqrt{\left(S E_{M X_{1}}\right)^{2}+\left(S E_{M X_{2}}\right)^{2}} \\
& S E_{M X_{1}-M X_{2}}=\sqrt{(1,15)^{2}+(1,48)^{2}} \\
& S E_{M X_{1}-M X_{2}}=\sqrt{1,3225+2,1904} \\
& S E_{M X_{1}-M X_{2}}=\sqrt{3,5129} \\
& S E_{M X_{1}-M X_{2}}=1,87
\end{aligned}
$$

Selanjutnya akan dilakukan pengujian hipotesis dengan menggunakan uji " $\mathrm{t}$ " dengan rumus:

$\mathrm{t}_{0}=\frac{M X_{2}-M X_{1}}{S E_{M X_{1}-M X_{2}}}=\frac{76,94-58,76}{1,87}=\frac{18,18}{1,87}$ $=9,72$ 
Berdasarkan penghitungan dengan uji " $\mathrm{t}$ " diperoleh $\mathrm{t}_{\text {hitung }}=9,72$ dan $t_{\text {tabel }}=1,69$. Karena $t_{\text {hitung }}$ yang diperoleh lebih besar dari $t_{\text {tabel }}$ yaitu 9,72>1,69, maka $h_{a}$ : terdapat pengaruh penerapan pendekatan variasi terhdap hasil belajar tortor Hata Sopisik siswa kelas IV SD Negeri 132403 Tanjungbalai diterima. Hal ini mmbuktikan bahwa dengan menerapkan pendekatan variasi berpengaruh yang signifikan terhadap hasil belajar tortor Hata Sopisik siswa kelas IV SD Negeri 132403 Tanjungbalai.

\section{PENUTUP}

\section{Kesimpulan}

Berdasarkan hasil penelitian yang telah diuraikan pada bab IV maka dapat diambil kesimpulan sebagai berikut:

1. Hasil belajar tortor Hata Sopisik siswa kelas IV SD Negeri 132402 Tanjungbalai sebelum menerapkan pendekatan variasi dalam proses pembelajaran dikategorikan baik dengan nilai rata-rata 58,76 .

2. Hasil belajar tortor Hata Sopisik siswa kelas IV SD Negeri 132402
Tanjungbalai setelah menerapkan pendekatan variasi dalam proses pembelajaran dikategorikan baik dengan nili rata-rata 76,94.

3. Adanya pengaruh yang signifikan pada penerapan pendekatan variasi terhadap hasil belajar tortor Hata Sopisik siswa kelas IV SD Negeri 132403 Tanjungbalai yang diperoleh dari hasil uji hipotesis $t_{0}=9,72$ pada taraf signifikan $5 \%$ dan $\mathrm{dk}=\mathrm{Zn}-1, \mathrm{t}_{\text {tabel }}$ $=1,69$ dengan demikian $\mathrm{t}_{0}>\mathrm{t}_{\text {tabel }}$ yakni 9,72>1,69.

\section{Saran}

Berdasarkan hasil penelitian ini, maka peneliti memberikan saran sebagai berikut:

1. Berdasarkan hasil penelitian, penerapan pendekatan variasi dapat membantu guru untuk mengahadapi permasalahan anak didik yang bervariasi sehingga dapat membantu untuk meningkatkan hasil belajar dan keefektifan proses pembelajaran, untuk itu disarankan kepada guru seni budaya untuk lebih memperhatikan proses 
pembelajaran dengan mereapkan pendekatan variasi.

2. Pendekatan variasi memerlukan kreatifitas guru untuk memecahkan berbagai masalah yang dihadapi anak didik dalam proses pembelajaran.

3. Disarankan agar penelitian selanjutnya tetap memperhatikan pendekatan, strategi, serta metode pembelajaran yang digunakan disekolah khususnya pembelajaran seni tari.

\section{DAFTAR PUSTAKA}

Arikunto.2009. Prosedur Penelitian. Jakarta: Rineka Cipta

Djamarah, Syaiful Bahri dan Zain, Aswan. 2014. Strategi Belajar Mengajar. Jakarta: Rineka Cipta.

Golda Simarmata. 2013. Husip-husip Dalam Tortor Hata Sopisik Pada Masyarakat Batak Toba. Skripsi.

Hasibuan, Ernita Sari. 2011. Pengaruh Pendekatan Matematika Realistik Terhadap Kemampuan Pemecahan Masalah Dan Komunikasi Matematis Siswa. Skripsi.

Huda, Miftahul. 2014. Model-model Pengajaran Dan Pembelajaran. Yogyakarta: Pustaka Pelajar.

Kusumo, Jati. 2011. Pengaruh Strategi Pembelajaran Peer Teaching Terhadap Hasil Belajar Menerapkan TEknik Elektronika Analog Dan Digital Dasar di SMK Dwitunggal Tanjung Morawa. Skripsi.

Manurung, Margaretta R. 2015. Pengaruh Model Pembelajaran Creative Problem Solving Dan Pendekatan Contextual Teaching And Learning Terhadap Hasil Belajar Akuntansi Siswa Kelas XI IS SMA N 11 Medan Tahun Pembelajaran 2014/2015. Skripsi. 
Samosir, Mely Christin Natalia. 2014. Penerapan Metode Demonstrasi Untuk Meningkatkan Hasil Belajar Tari Melayu Materi Mak Inang Di SMP Bina Budaya Kabupaten Asahan. Skripsi.

Nurwani. 2007. Pengetahuan Tari. Diktat Jurusan Sendratasik. FBS Universitas Negeri Medan.

Purwanto. 2011. Evaluasi Hasil Belajar. Yogyakarta: Pustaka Pelajar

Rusman. 2014. Model-model Pembelajaran Mengembangkan Profesionalisme Guru. Jakarta: Raja Grafindo Persada.

Subagyo, P.Joko. 2015. Metode Penelitian Dalam Teori Dan Praktik. Jakarta: Rineka Cipta.

Sudijono, Anas. 2008. Pengantar Statistik Pendidikan. Jakarta: Raja Grafindo Persada.

Sudjana, Nana. 2005. Metode Statistika. Bandung:Tarsito

Sujarweni, Wiratna. 2014. Metodologi Penelitian. Yogyakarta: Pustaka Baru Press.

Suryosubroto, B. (1997). Proses Belajar Mengajar Di Sekolah. Jakarta: Rineka Cipta.

Triana, Dinny Devi. 2013. Evaluasi Pembelajaran Ruang Lingkup
Seni. Jakarta Timur: Inti Prima Promosindo

http://mahmud09-

kumpulanmakalah.blogspot.c o.id/2012/07/macam-macampendekatan-dalamproses.html? $\mathrm{m}=1$

http://jhonmiduk8.blogspot.co.id/201 5/05/pengertian pembelajaran-menurutpara.html?m=1

http://www.informasiahli.com/2015/ 07/pengertian-pembatasanmasalah-dalampenelitian.html

http://biellyherdian.blogspot.co.id/20 09/07/hakekat-pembelajaranpendekatan.html? $\mathrm{m}=1$

http://zuraidasyahla.blogspot.co.id/2013/10 /instrumen-dan-teknikpengumpulan-data.html? $\mathrm{m}=1$

http://www.pengertianpakar.com/201 5/05/teknik-pengumpulandan-analisis-data.html 